DOI: https://doi.org/10.35699/2238-037X.2019.12020

\title{
O PERFIL PROFISSIONAL DOS PROFESSORES INICIANTES E OS FIOS CONDUTORES DAS PRÁTICAS PEDAGÓGICAS ${ }^{1}$ \\ The professional profile of beginner teachers and the guiding principles of pedagogical practices
}

\author{
CIPRIANI, Andreza² \\ KORMANN TOMAZONI, Eliane ${ }^{3}$ \\ SELPA HEINZLE, Marcia Regina ${ }^{4}$
}

\begin{abstract}
REsumo
Nesta pesquisa, propomos-nos a analisar duas dimensões, o perfil profissional dos professores dos cursos de engenharia com menos de cinco anos de atuação, e os fios condutores das suas práticas pedagógicas em duas Instituições de Ensino Superior de Santa Catarina. O aporte teórico foi baseado em alguns autores como Huberman (1992); Nóvoa (1995) e Tardif (2008), para compreensão dos processos constitutivos e das fontes sociais de aquisição da formação docente. A presente pesquisa tem caráter qualitativo e realizou-se por meio de aplicação de questionário on-line com perguntas abertas, de múltiplas escolhas e questões seguindo uma escala de resposta do tipo Likert. Para a interpretação e análise das informações obtidas, aplicou-se a metodologia de Análise de Conteúdo, organizando os dados em categorias, as quais nos possibilitaram um mapeamento do perfil dos professores iniciantes que atuam nos cursos de engenharias, assim como os elementos que fortalecem e dificultam a docência e as principais práticas pedagógicas. As análises decorridas a partir dos dados obtidos reforçam os apontamentos contidos na literatura sobre a fragilidade da profissionalidade docente e dificuldades encontradas na trajetória nos primeiros anos de docência. Desse modo, o presente estudo nos proporcionou compreender os desafios presentes nas universidades, no que tange à complexidade e à singularidade em ser professor iniciante.
\end{abstract}

Palavras-chave: Perfil docente. Professor iniciante. Práticas pedagógicas.

\section{Abstract}

In this research we proposed to analyze two dimensions, the professional profile of the teachers in the engineering courses with less than five years of service, and the conductive threads of their pedagogical practices in two Universities of Santa Catarina. To comprehend the teachers' formation constitutive processes and social resources, we used theory contributions by Huberman (1992), Nóvoa (1995), and Tardif (2008). The present research has a qualitative approach and was performed through an online questionnaire with open questions, multiple choices and questions following a Likert type response scale. For the interpretation and analysis of the information obtained, the Content Analysis methodology was applied, organizing the data into categories, which enabled us to map the profile of the beginner teachers who work in the engineering courses, as well as the elements that strengthen and teaching and

\footnotetext{
${ }^{1}$ Essa pesquisa foi financiada pela própria instituição a partir do edital interno.

${ }^{2}$ Mestre em Química pela Universidade Regional de Blumenau -FURB, Graduação em Química pela Universidade Regional de Blumenau - FURB. Atua na área de Educação em Química desenvolvendo projeto de parceria com a FURB, intitulado LENQUI - Laboratório de Ensino de Química. E-mail: andrezacipriani@hotmail.com.

3 Mestre em Educação pela Universidade Regional de Blumenau -FURB, Graduação em Pedagogia pela Universidade do Vale do Itajaí - UNIVALI, Pós-graduação em nível de especialização em Fundamentos da Educação pela Universidade Regional de Blumenau -FURB. Atualmente é docente no Centro Universitário de Brusque - UNIFEBE, em curso presencial de Pedagogia e em EaD. E-mail: eliane.kormann@unifebe.edu.br.

${ }^{4}$ Doutora em Educação pela Universidade Estadual de Campinas - UNICAMP, Mestre em Educação pela Universidade Regional de Blumenau - FURB, Especialização em Ativação de Processos de Mudança na Formação Superior de Profissionais de Saúde - ENSP FIOCRUZ, Especialização em Dificuldades de Aprendizagem - UNIPLAC. Graduação em Pedagogia pela Universidade do Planalto Catarinense - UNIPLAC. Professora e Pesquisadora no Programa de Pós-Graduação em Educação na Universidade Regional de Blumenau-FURB.E-mail: selpamarcia@gmail.com.
}

Trabalho \& Educação | v.28 | n.2 | p.79-95 | maio-ago | 2019 
main pedagogical practices. The analysis based on the data obtained reinforces the notes contained in the literature on the fragility of teaching professionalism and difficulties encountered in the trajectory in the first years of teaching. In this way, the present study allowed us to understand the challenges present in universities, regarding the complexity and the singularity of being a beginning teacher.

Keywords: Teaching profile. Beginner teacher. Pedagogical practices.

\section{INTRODUÇÃO}

As políticas de implantação, ampliação e/ou reestruturação de IES (Instituições de Ensino Superior), no Brasil, apresentam-se como alternativas positivas no que diz respeito ao aumento do número de discentes ingressantes, embora, na sua maioria, em instituições privadas. Em decorrência disso, nos últimos anos, observa-se um crescimento significativo de professores iniciantes no ensino superior, sendo estes, muitas vezes, jovens, recém-doutores que precisam aliar sua formação com as exigências da profissão docente (ZANCHET; FELDKERCHER, 2016). Dessa forma, no Brasil, as discussões referentes aos saberes e aos desafios do trabalho do professor iniciante são foco de inúmeras pesquisas e demonstram a necessidade da melhora das condições de trabalho, bem como a criação de políticas públicas e institucionais que visam à qualidade do ensino e formação desses professores (BOLZAN; POWACZUK, 2013); (PASSOS; SILVA; MARQUES, 2014).

De acordo com os dados disponibilizados pelo INEP (Instituto Nacional de Estudos e Pesquisas Educacionais Anísio Teixeira), em suas sinopses estatísticas, o número de instituições de educação superior é de 2.407, sendo que, em 2016, foram ofertados 34.366 cursos, pertencentes às categorias administrativas públicas e privadas. Os cursos de bacharelado concentram a maioria dos ingressantes da educação superior $(61,5 \%)$.

No Brasil, até 1996, os cursos de engenharia eram regulados pela Resolução 48/76 de 27 de abril de 1976, a qual fixava os conteúdos mínimos, duração dos cursos de graduação e somente definia suas áreas de habilitação (MEC/CFE, 1976). A partir da Resolução 11/2002, a qual regulamenta as Diretrizes Curriculares Nacionais do Curso de Graduação em Engenharia, os cursos de graduação passaram a contemplar em seu conteúdo uma nova base pedagógica, focando no desenvolvimento de habilidades e competências, para resolutividade de problemas reais considerando seus aspectos políticos, econômicos, sociais, ambientais e culturais.

Pesquisas apontam, contudo, dificuldades que os estudantes enfrentam nos cursos de engenharia em relação às questões pedagógicas dos engenheiros-professores, por não entenderem a natureza da profissão, limitando-se a expor uma expressiva quantidade de conteúdos desconectados da realidade, prejudicando o processo de ensinoaprendizagem (MENESTRINA; BAZZO, 2004; LACLAUSTRA et al., 2008). De acordo com Hidalga (2006), os professores dos cursos de engenharia se articulam levando em consideração alguns tipos de saberes: os referentes à experiência, os didáticocurriculares, os atitudinais e os críticos-contextuais. Nitsch, Bazzo e Tozzi (2004) alertam que o engenheiro que se transforma em professor, acaba descobrindo um novo ambiente para o qual não teve formação pedagógica. Sendo assim, fica evidente a necessidade da diferenciação entre os objetos de trabalho no campo da engenharia e da docência no Ensino Superior.

A formação para a docência é destacada como fundamental para a melhoria da qualidade do ensino superior, visando à superação de um modelo tradicionalista e 
conservador, no qual "o processo de ensino passa a ser uma indisfarçada afirmação da realidade do objeto por parte do professor e uma apassivada memorização de informações técnicas, de preferência matematizadas, por parte dos alunos" (BAZZO; PEREIRA; VON LINSINGEN, 2008, p. 23). De acordo com Laudares (2010), as práticas docentes de muitos engenheiros-professores apoiam-se basicamente em valores, crenças e representações sociais acerca do que é ser professor, que são construídas ao longo de sua história de vida familiar e escolar, bem como a partir de suas interações com seus pares.

Somada a essa problemática, inclui-se a clássica discussão dos professores iniciantes, independentemente de sua área de atuação, que assumem a docência em condições desfavoráveis, com contratos de trabalho temporários e paradoxalmente com formação profissional incompleta e deficitária (SAVIANI, 2009). Ainda possui renumeração insignificante, desde longa data, tornando a profissão pouco atraente, o que contribui de maneira significativa para o abandono da carreira (ALVES; PINTO, 2011). Sendo assim, é notável que esses profissionais em início de carreira faceiem dificuldades, influenciando seu desenvolvimento profissional docente. Pesquisas ressaltam, no entanto, a escassez de estudos que questionem acerca da formação específica para estes professores, mesmo que alguns estudos apontem tal necessidade e relevância (PAPI; MARTINS, 2010).

Nesse sentido, esta pesquisa de caráter qualitativo, realizada por meio de entrevistas semi-estruturadas, utilizando-se de formulário on-line, propôs-se a identificar o perfil profissional dos professores iniciantes que atuam nos cursos de engenharia, assim como os fios condutores de suas práticas pedagógicas. A partir das respostas obtidas, foram analisados os dados em comum, tendo como norteadores para a análise de conteúdo alguns questionamentos: como se constitui a identidade do professor em início de carreira nos cursos de engenharia? Quais os fios condutores de suas práticas pedagógicas? Quais as fragilidades e os desafios encontrados nesse processo?

\section{Profissionalidade docente: fios Condutores}

Segundo Tardif (2014, p. 16) os saberes docentes "são uma realidade social materializada através de uma formação, de programas, de práticas coletivas, de disciplinas escolares, de uma pedagogia institucionalizada, etc, e também, ao mesmo tempo, os saberes dele". Sendo assim, o autor situa o saber do professor na interface entre o "individual e o social, entre o ator e o sistema" o qual se dá a partir de seis fios condutores. O primeiro diz respeito ao saber e trabalho - o saber do professor compreende-se na íntima relação com o trabalho na escola e na sala de aula: são as relações mediadas pelo trabalho que fornecem princípios para enfrentar e solucionar situações cotidianas. O segundo fio condutor é a diversidade do saber, pois percebe que o saber dos professores é plural, compósito e heterogêneo, por envolver, no próprio exercício da ação docente, conhecimentos e um saber-fazer bastante variados e, normalmente, de natureza diferente. O terceiro fio condutor é a temporalidade do saber - reconhece o saber dos professores como temporal, uma vez que o saber é adquirido no contexto de uma história de vida e de uma carreira profissional. O quarto fio condutor, denominado a experiência de trabalho enquanto fundamento do saber, focaliza os saberes oriundos da experiência do trabalho cotidiano como alicerce da prática e da competência profissional. O quinto fio condutor, saberes humanos a respeito de saberes humanos, manifesta a ideia de trabalho interativo, um trabalho em que o trabalhador se 
relaciona com o seu objeto de trabalho fundamentalmente por meio da interação humana. O sexto e último fio, saberes e formação profissional, é derivado dos anteriores, ou seja, expressa a necessidade de repensar a formação para o magistério, levando em consideração os saberes dos professores e as realidades específicas de seu trabalho cotidiano.

Nessa perspectiva, pode-se compreender que os saberes docentes são temporais, personalizados e situados, carregando as marcas do ser humano, podendo ser definidos "como um saber plural, formado pelo amálgama, mais ou menos coerente, de saberes oriundos da formação profissional e de saberes disciplinares, curriculares e experienciais" (TARDIF, 2014, p. 36). Para que esses saberes docentes possam ser concretizados, no entanto, é preciso o conhecimento da pedagogia, da arte de ensinar:

Não existe processo de ensino-aprendizagem sem pedagogia, embora se manifeste com frequência uma pedagogia sem reflexão pedagógica. Essa simples constatação permite invalidar a crença de que certos professores (principalmente na universidade!) que pensam não estarem fazendo uso da pedagogia simplesmente porque retomam rotinas repetidas há séculos. (TARDIF, 2001, p. 20-21)

De fato, considerar modelos que identifiquem e classifiquem os saberes dos professores não é tarefa fácil. É preciso, entretanto, destacar fenômenos que são importantes, os quais tentam "dar conta do pluralismo do saber profissional, relacionando-o com os lugares nos quais os próprios professores atuam, com as organizações que os formam e/ou nas quais trabalham, com seus instrumentos de trabalho e, enfim, com sua experiência de trabalho" (TARDIF, 2014, p.62-63). Neste contexto, o Quadro 1 evidencia vários fenômenos importantes que fazem parte da trajetória profissional e da prática cotidiana do docente, o que torna possível ter uma visão mais ampla e clara dos saberes dos professores como um todo.

QUADRO 1- Os saberes dos professores

\begin{tabular}{|l|l|l|}
\hline \multicolumn{1}{|c|}{ Saberes dos professores } & \multicolumn{1}{|c|}{ Fontes Sociais de aquisição } & $\begin{array}{l}\text { Modos de integração no trabalho } \\
\text { docente }\end{array}$ \\
\hline Saberes pessoais dos professores & $\begin{array}{l}\text { A vida, o ambiente de vida, a } \\
\text { educação no sentido lato, etc. }\end{array}$ & $\begin{array}{l}\text { Pela história de vida e pela } \\
\text { socialização primária }\end{array}$ \\
\hline $\begin{array}{l}\text { Saberes provenientes da formação } \\
\text { escolar anterior }\end{array}$ & $\begin{array}{l}\text { A escola primária e secundária, os } \\
\text { estudos pós-secundários não } \\
\text { especializados, etc. }\end{array}$ & $\begin{array}{l}\text { Pela formação e pela socialização } \\
\text { pré-profissionais }\end{array}$ \\
\hline $\begin{array}{l}\text { Saberes provenientes da formação } \\
\text { profissional para o magistério }\end{array}$ & $\begin{array}{l}\text { Os estabelecimentos de formação de } \\
\text { professores, os estágios, os cursos } \\
\text { de reciclagem, etc. }\end{array}$ & $\begin{array}{l}\text { Pela formação e pela socialização } \\
\text { dos profissionais nas instituições de } \\
\text { formação de professores }\end{array}$ \\
\hline $\begin{array}{l}\text { Saberes provenientes dos programas } \\
\text { e livros didáticos usados no trabalho }\end{array}$ & $\begin{array}{l}\text { A utilização das "ferramentas" dos } \\
\text { professores: programas, livros } \\
\text { didáticos, cadernos de exercícios, } \\
\text { fichas, etc. }\end{array}$ & $\begin{array}{l}\text { Pela utilização das "ferramentas" de } \\
\text { trabalho, sua adaptação às tarefas }\end{array}$ \\
\hline $\begin{array}{l}\text { Saberes provenientes de sua-própria } \\
\text { experiência na profissão, na sala de } \\
\text { aula e na escola }\end{array}$ & $\begin{array}{l}\text { A prática do ofício na escola e na sala } \\
\text { de aula, a experiência dos pares, etc. }\end{array}$ & $\begin{array}{l}\text { Pela prática do trabalho e pela } \\
\text { socialização profissional }\end{array}$ \\
\hline \begin{tabular}{l} 
Fonte: Tardif (2014). \\
\hline
\end{tabular}
\end{tabular}

Diante do exposto, obsena-se que esse modelo tipológico de análise baseado na origem social enfatiza os saberes que os professores utilizam constantemente, fazendo uso das mais variadas ferramentas. Também se constata a natureza social do saber profissional, a qual provém de lugares sociais anteriores à formação. Assim, "o saber profissional está, de certo modo, na confluência entre várias fontes de saberes provenientes da história de vida individual, da sociedade, da instituição escolar, dos atores educativos, dos lugares de formação, etc.". (TARDIF, 2014, p. 64). 
Cunha (2007) traz importantes contribuições ao se pensar na profissão docente. Para a autora, o professor, enquanto profissional, estaria mais bem situado no conceito de profissionalidade do que no de profissão, devido ao fato de esta ser uma "profissão em ação, em processo, em movimento" (p. 14). Destaca ainda que, a partir dessa perspectiva, o professor deixa de ser um reprodutor mecânico e passa a buscar, na reflexão de sua prática, a resolução para os problemas profissionais cotidianos.

Logo, entende-se que o ensino não pode se fixar ao tempo/espaço do local onde ele acontece, porque é nesse movimento não fixado de produção do conhecimento que reside a profissionalidade docente, em que "o professor não mais representa o tradicional transmissor de conhecimentos". (CUNHA, 2007, p. 16). Para tanto, "a troca de experiências e a partilha de saberes consolidam espaços de formação mútua, nos quais cada professor é chamado a desempenhar, simultaneamente, o papel de formador e de formado" (NÓVOA, 1995, p. 26). Ainda cabe destacar que:

O diálogo entre os professores é fundamental para consolidar saberes emergentes da prática profissional. Mas a criação de redes colectivas de trabalho constitui, também, um factor decisivo de socialização profissional e de afirmação de valores próprios da profissão docente. O desenvolvimento de uma nova cultura profissional dos professores passa pela produção de saberes e de valores que dêem corpo a um exercício autónomo da profissão docente (NÓVOA, 1995, p. 26).

O professor passa a assumir uma nova profissionalidade, com um caráter mais crítico e reflexivo, sendo assim, é possível perceber a importância da formação dos professores, a qual é amplamente reconhecida como promotora de uma prática docente melhor sistematizada e de uma educação para a inserção social. Essa também é um mecanismo importante na melhoria da qualidade da educação, no qual o professor deva ter o compromisso de reconhecer a sua profissão, identificando quais saberes são usados em sua prática, quais não são mobilizados e que deveriam ser e quais saberes ainda não foram identificados (BORGES e TAUCHEN, 2017). Para isso, tornam-se importantes as políticas públicas que alicerçam os professores em sua profissão, assim como é de suma importância discutir, de forma propositiva e coletiva, a política institucional de formação docente, incluindo a dimensão da formação dos formadores.

\section{Professores iniciantes em debate: tecendo desafios}

As ações de formação continuada estão ganhando espaço dentro das universidades, desde cursos pontuais direcionados aos docentes como em projetos ou políticas institucionais que visam à promoção de práticas formativas ao magistério superior (ALMEIDA, 2012). O estudo realizado por Papi e Martins (2010) demonstra, porém, que as iniciativas ainda são rasas e revelam a necessidade de mais estudos que explorem essa problemática no que diz respeito às ações de formação para professores iniciantes.

A Coordenação de Aperfeiçoamento de Pessoal de Nível Superior - CAPES (2002) oficializou o Estágio Docência, a partir da Portaria $n^{\circ}$ 52, de 26 de setembro de 2002, como uma forma de docência orientada aos pós-graduandos, mas apenas aos bolsistas dessa agência financiadora. Essa iniciativa, mesmo que isolada, não é o suficiente e sinaliza uma preocupação que vem aumentando no meio acadêmico. De acordo com Pimenta e Anastasiou (2002), os professores do ensino superior das diferentes áreas preferem ser identificados como profissionais autônomos: físico, advogado, médico, 
engenheiro, pois o título de professor de qualquer outra área do conhecimento, sozinho, parece sugerir uma identidade menor.

Considera-se também, nesse contexto, o professor iniciante, no que se refere ao seu desenvolvimento profissional. $O$ desenvolvimento profissional de professores denominado como "ciclo de vida profissional dos professores" (HUBERMAN, 1989) compreende um processo contínuo que agrega conhecimentos, experiências, atitudes, concepções e práticas ao longo da carreira docente. Ainda Huberman (1992); Garcia (1999) e Cavaco (1995) apontam que o período de professor iniciante está compreendido entre os cinco primeiros anos de atuação profissional.

Nesse sentido, a formação assume maior relevância para os professores iniciantes, pois é nessa fase que ocorre uma intensificação do aprendizado profissional e pessoal, a transição de estudante para professor, a condição de trabalho leigo para profissional, de inexperiente para experiente, de identificação, socialização e aculturação profissional. Trata-se de um processo de transição do status de estudante para professor profissional (GARCIA, 1999). E, ao assumir responsabilidades, o profissional se vê diante de desafios, expectativas e inseguranças. Para Cavaco (1995), os primeiros anos deixam marcas profundas na maneira como se pratica a profissão.

Dessa forma, o início da docência é marcado por intensas descobertas sobre a prática e seus problemas, e sobre as alternativas possíveis para resolvê-los. $\mathrm{O}$ apoio nessa fase é importante, vindo dos coordenadores de curso, da assessoria pedagógica da instituição, de momentos contínuos de formação e dos próprios professores mais experientes. Para Garcia (1999), esse período inicial é o mais difícil e crítico na carreira dos professores. É denominado "choque com a realidade" expressa pela discrepância entre as expectativas dos novos profissionais e a realidade em que atuam, cotejando os "ideais missionários" construídos durante a sua formação inicial e as dificuldades que enfrentam no cotidiano da prática pedagógica. Os desafios que compõe essa etapa: a sobrevivência e a descoberta abrandam as dificuldades, pois o professor experimenta sentimentos de "exaltação por estar, finalmente, em situação de responsabilidade (ter a sua sala de aula, os seus alunos, o seu programa), por se sentir num determinado corpo profissional" (HUBERMAN, 1992, p. 59).

Os estudos sobre o início da carreira do professor desempenham importante papel na compreensão do processo de inserção e estabilidade na profissão possibilitando aos formadores de professores pensarem novas propostas de formação docente. Refletir a respeito dessas dificuldades dos professores iniciantes, os desafios encontrados e compartilhados, pode levar à superação e a um maior crescimento profissional. Reali, Trancredi e Mizukami (2008) destacam que os professores iniciantes, em sua grande maioria, não têm espaços de discussão a respeito da docência, tendo assim, dificuldades em gerir o processo de ensino-aprendizagem.

Há, portanto, necessidade de repensar a inserção do professor iniciante na prática pedagógica, não somente dos professores dos cursos de engenharias, campo dessa pesquisa, mas de todas as áreas, pois são múltiplos os desafios docentes pela pluralidade de saberes que constituem esse cenário coletivo da profissão e individual do sujeito professor.

\section{Apontamentos metodológicos}


A presente pesquisa tem caráter qualitativo e realizou-se por meio de aplicação de questionário on-line com perguntas abertas, de múltiplas escolhas e questões seguindo uma escala de resposta do tipo Likert, de acordo com Silva Junior e Costa (2014, p. 5), "a escala de verificação de Likert consiste em tomar um construto e desenvolver um conjunto de afirmações relacionadas à sua definição, para as quais os respondentes emitirão seu grau de concordância".

Para o estudo, realizou-se primeiramente um levantamento do número de professores do curso de engenharia que ingressaram, por meio de processo seletivo, nos últimos cinco anos, em duas IES de Santa Catarina, uma de caráter público e outra comunitária. Na sequência, encaminhou-se um convite para todos os concursados para participarem da pesquisa e, após o aceite, enviou-se um questionário semiestruturado, utilizando-se de formulário on-line. Sendo assim, a pesquisa desenvolveu-se com sete professores na área das engenharias com menos de cinco anos de carreira docente. $\mathrm{O}$ instrumento metodológico utilizado nesta pesquisa respeitou os procedimentos éticos estabelecidos para a pesquisa científica em Ciências Humanas.

Para a interpretação e análise das informações obtidas, aplicou-se a metodologia de Análise de Conteúdo (BARDIN, 2010). Cabe esclarecer que os princípios dessa metodologia buscam compreender criticamente o sentido das comunicações, seus conteúdos manifestos e as significações explícitas. Assim, os dados foram organizados em categorias, as quais possibilitaram um mapeamento do perfil dos professores iniciantes que atuam nos cursos de engenharias e as práticas docentes constituídas em materializados de forma individual e social, sob a ótica do ator e do sistema, constituindose a partir de fios condutores (TARDIF, 2014).

A partir do objetivo desta pesquisa que tratava de analisar o perfil profissional dos professores iniciantes que atuam nos cursos de engenharia e os fios condutores de suas práticas pedagógicas, elencaram-se, no questionário, perguntas que contemplavam duas dimensões, a primeira, sobre o perfil profissional: a) Atuação profissional e jornada de trabalho b) Atividades de pesquisa e extensão e c) Participação ativa como membro nos conselhos institucionais. Na segunda dimensão, foram analisados os fios que conduzem a prática docente, elencando-se perguntas relacionadas: a) à fase de desenvolvimento profissional docente e escolha da profissão; b) às condições de trabalho e dificuldades da profissão; c) à formação continuada e d) às metodologias de ensino e avaliação da aprendizagem.

O questionário estruturou-se com questões de múltipla escolha, duas questões abertas e questões de escala de resposta do tipo Likert de três pontos.

Para a construção do referencial teórico, o aporte foi baseado em alguns autores como Huberman (1992); Nóvoa (1995) e Tardif (2008), que nortearam esta pesquisa no desvelamento de elementos da profissionalização docente, na compreensão dos processos constitutivos e das fontes sociais de aquisição da formação docente, tornando possível dialogar e refletir a respeito dos professores em início de carreira e seu papel profissional.

\section{Resultados e Discussão}

\subsection{Perfil Profissional dos docentes}


Para a análise dos dados, fez-se, inicialmente, uma tabulação das informações contidas nas três primeiras perguntas do questionário, a fim de se identificar o perfil dos participantes da pesquisa. No Quadro 2, são apresentadas as características dos professores sujeitos do estudo, em que estão especificadas: as áreas de formação, a experiência na docência universitária (em termos de tempo de atuação) e disciplinas ministradas. De acordo com a tabela supracitada, pôde-se verificar que a maioria dos professores possui formação em cursos de graduação em Engenharia, ressaltando-se apenas dois professores com formações distintas, sendo elas Arquitetura e Urbanismo e Licenciatura em História e que atuam nos cursos de engenharia. No que diz respeito à formação quanto à Pós-Graduação, apenas um professor entrevistado possui Doutorado, quatro indicaram ter Mestrado e dois apenas Graduação. Dos sete professores participantes, somente um apresentou tempo de atuação como docente universitário de um ano, sendo o menor tempo apresentado entre os professores participantes.

Em relação às disciplinas ministradas no ensino superior, a maioria dos professores elencou entre duas a dez disciplinas nas quais atuaram em todo seu tempo de carreira docente. Os professores que possuem formação nas áreas de Engenharia, ministraram disciplinas específicas contidas na maioria dos cursos de Engenharia Civil e Mecânica. Ao analisar as disciplinas ministradas pelos professores formados em outras áreas, como Arquitetura e Urbanismo, percebeu-se a atuação nas disciplinas de Projeto Arquitetônico, História da Arquitetura, Planejamento Urbano, Conforto Ambiental Térmico e Estudos da Paisagem da Cidade, e outras voltadas diretamente aos cursos de áreas afins.

QUADRO 2- Características dos professores

\begin{tabular}{|c|c|c|c|c|}
\hline Entrevistados & Graduação & Pós-Graduação & $\begin{array}{l}\text { Tempo } \\
\text { de } \\
\text { atuação } \\
\text { docente } \\
\text { (anos) }\end{array}$ & Disciplinas ministradas \\
\hline P1 & $\begin{array}{l}\text { Engenheraia } \\
\text { Química }\end{array}$ & Doutorado & 5 & $\begin{array}{lccc}\text { Operações } & \text { Unitárias/ Reatores Químicos/ } & \text { Quías } \\
\text { Modelagem Matemática/ Simulação de de } & \text { de } \\
\text { Processos/Fenômenos de Transporte } & \end{array}$ \\
\hline P2 & $\begin{array}{l}\text { Engenharia } \\
\text { Civil }\end{array}$ & Não possui & 5 & \begin{tabular}{llrr} 
Desenho Técnico I e & II/Construção Civil I e \\
II/Suprimentos & na & \multicolumn{2}{c}{ Construção } \\
Civil/Sustentabilidade na Construção & Civil/ \\
Instalações Hidrossanitárias/Projeto & de \\
Pesquisa/Estágio Supervisionado I e II &
\end{tabular} \\
\hline P3 & $\begin{array}{l}\text { Engenharia } \\
\text { Mecânica }\end{array}$ & $\begin{array}{l}\text { Mestrado em } \\
\text { Engenharia } \\
\text { Mecânica }\end{array}$ & 1 & Metrologia /Elementos de Máquina \\
\hline P4 & $\begin{array}{l}\text { Engenharia } \\
\text { Civil }\end{array}$ & $\begin{array}{l}\text { Mestrado em } \\
\text { Tecnologias de } \\
\text { Saneamento } \\
\text { Ambiental } \\
\end{array}$ & 4 & $\begin{array}{l}\text { Materiais de Construção I, II e III/Patologia das } \\
\text { Construções/Fundações/ Sistemas Estruturais/ } \\
\text { Sistemas Estruturais Madeira }\end{array}$ \\
\hline P5 & $\begin{array}{l}\text { Engenharia de } \\
\text { Produção Civil }\end{array}$ & Não possui & 2,5 & Construção Civil I/Materiais de Construção I e II \\
\hline P6 & $\begin{array}{c}\text { Arquitetura e } \\
\text { Urbanismo }\end{array}$ & Mestrado & 4 & Projeto Arquitetônico \\
\hline P7 & $\begin{array}{l}\text { Licenciatura em } \\
\text { História e } \\
\text { Arquitetura e } \\
\text { Urbanismo }\end{array}$ & $\begin{array}{c}\text { Mestrado em } \\
\text { História }\end{array}$ & 4 & $\begin{array}{l}\text { História da Arquitetura (6 distintas)/Planejamento } \\
\text { Urbano/ Projeto Arquitetônico/ Conforto } \\
\text { Ambiental Térmico/ Estudos da Paisagem da } \\
\text { Cidade }\end{array}$ \\
\hline
\end{tabular}

A posterior análise dos dados, no que diz respeito à atuação profissional e jornada de trabalho, revelou que os professores participantes já atuaram em Instituição Pública Federal (18\%) e Municipal (9\%), sendo que a maioria sinalizou sua atuação 
principalmente em Instituição Privada ou em Centro Comunitário, sendo respectivamente o total de 37 e $36 \%$ dos participantes. Destaca-se que nenhum dos participantes apontou ter atuado em Instituição Pública Estadual, conforme apresentado no Gráfico 1.

GRÁFICo 1- Atuação dos profissionais participantes da pesquisa em instituições de ensino

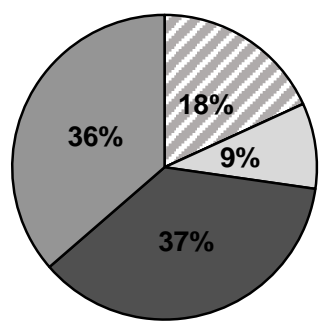

$$
\begin{aligned}
& \text { ๑Pública Federal } \\
& \text { 口Pública Estadual } \\
& \text { 口Pública Municipal } \\
& \text { 口 Instituição Privada } \\
& \text { 口Centro Comunitário }
\end{aligned}
$$

Fonte: as autoras.

De acordo com o último Censo da Educação Superior realizado pelo INEP em 2017, o número total de professores atuantes no Ensino Superior no Brasil soma o montante de 380.673. Cerca de $55 \%$ desse contingente atua em IES privadas, corroborando com o maior valor apresentado (37\%) pelos professores desta pesquisa. No que diz respeito à formação desses professores, 41,35\% são doutores, 39\% mestres e apenas 1,15\% apresentam ter graduação. No que tange aos resultados desta pesquisa, observa-se, no quadro 2, que apenas um professor sinalizou possuir doutorado, quatro professores possuem mestrado e dois somente graduação. Uma característica marcante evidenciada no Censo de 2017, é que, nas Instituições Públicas, a maioria dos docentes trabalha em tempo integral (85,6\%), já as Instituições Privadas contam com a prevalência de professores atuantes em tempo parcial $(40,5 \%)$, o que permite a estes trabalhar em mais de uma instituição de ensino e/ou exercer outra atividade profissional.

Os resultados aqui apresentados evidenciaram que a carga horária semanal de trabalho na instituição atual dos professores e o tempo de dedicação ao trabalho docente universitário variaram entre 8 a 40 horas semanais (Gráfico 2). Referente à carga horária semanal de trabalho e ao tempo dedicado à profissão, é possível perceber que, em média, $43 \%$ dos professores participantes dedicam mais horas ao trabalho docente do que de fato possuem de carga horária semanal de trabalho. Esses dados indicam possíveis dificuldades que estes profissionais enfrentam tanto no que diz respeito aos compromissos da profissão quanto ao investimento em sua carreira docente. Junges e Behrens (2015) apontam que essa questão acerca do tempo de dedicação ao trabalho docente é algo que poderia ser revisto pelas instituições de ensino superior, propiciando melhores condições para que os professores possam também dedicar-se aos próprios estudos e processos formativos, não abrindo mão de outras atividades das quais dependem a qualidade do ensino. 
GRÁFICO 2- Gráfico à esquerda se refere à carga horária semanal de trabalho; Gráfico à direita se refere à carga horária semanal dedicada ao trabalho docente universitário

CH Semanal de Trabalho

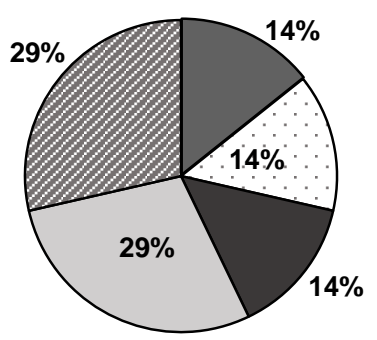

CH Semanal de Dedicação

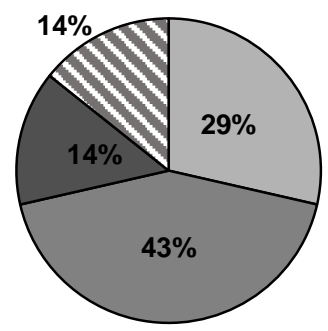

a $10 \mathrm{hr} / \mathrm{semana}$

口10 a $20 \mathrm{hr} / \mathrm{semana}$

$\square 20$ a $30 \mathrm{hr} /$ semana

口30 a $40 \mathrm{hr} /$ semana

Acima de $40 \mathrm{hr} /$ semana

Fonte: as autoras.

No que tange ao envolvimento dos profissionais em início de carreira com projetos de pesquisa e extensão, de acordo com os dados obtidos, observamos que todos os professores participam de projetos de pesquisa, porém apenas 30\% atuam em projetos de extensão. Ainda em relação à participação ativa como membro nos Conselhos de Curso, do total de participantes na pesquisa, $71 \%$ são membros de Colegiados de Cursos e 57\% fazem parte do Núcleo Docente Estruturante. Em relação à atuação em Programas de Pós-Graduação, $86 \%$ dos professores não participam de nenhum Programa (Gráfico 3), o que pode estar relacionado à titulação dos participantes nesta pesquisa, apenas um professor possuir doutorado.

De acordo com as características de universidade, três são as funções atribuídas aos professores universitários: o ensino, a pesquisa e extensão. No sentido concreto, Veiga (2006) estabelece que a docência configura o trabalho dos professores. Percebe-se, contudo, que estes desempenham um conjunto de funções que excedem a tarefa de ministrar aula. Sendo assim, tendo como base as informações obtidas, consideramos que os professores participantes não têm uma identidade única, suas características variam em relação às instituições de ensino nas quais exercem docência, e também de acordo com a trajetória de vida e de formação profissional de cada um.

GRÁFICo 3- Atuação dos professores por atividades
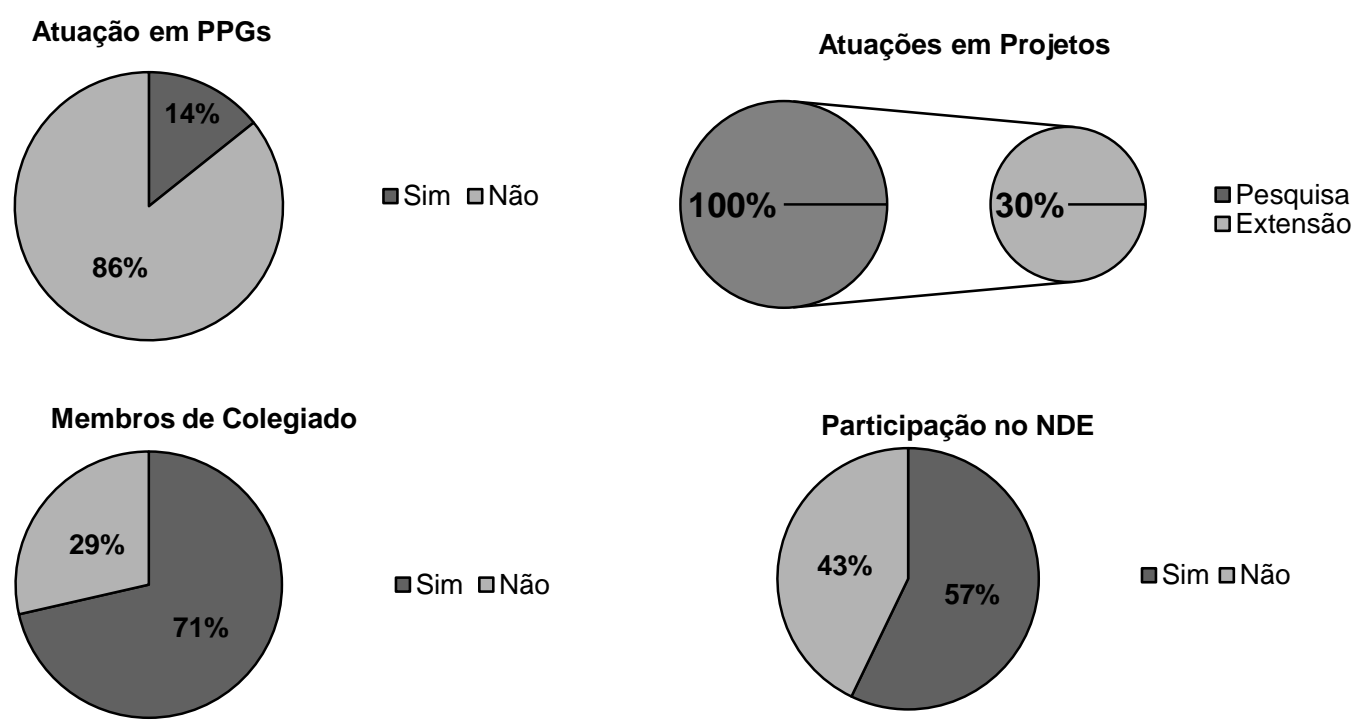

Fonte: as autoras. 


\subsection{OS FIOS CONDUTORES DA PRÁTICA PEDAGÓGICA}

De acordo com Feiman (2001 apud Nono, 2011, p. 19), "os primeiros anos da profissão docente representam um período intenso de aprendizagem e influenciam não apenas a permanência do professor na carreira, mas também o tipo de professor que o iniciante virá a ser". Assim, as experiências vivenciadas pelos professores em início de carreira têm influência direta sobre a sua decisão de continuar ou não na profissão, ao mesmo tempo, trata-se de um tempo de aprendizagem intensa, que pode traumatizar, e contraditoriamente despertar no professor a necessidade de sobreviver na profissão (HUBERMAN, 1992).

Em relação à escolha da profissão, os dados obtidos (Gráfico 4) apontam que as experiências vivenciadas pelos professores, em seus períodos iniciais de formação profissional, foram determinantes na escolha da carreira como docente universitário.

GRÁFICO 4 - As escolhas pela profissão docente
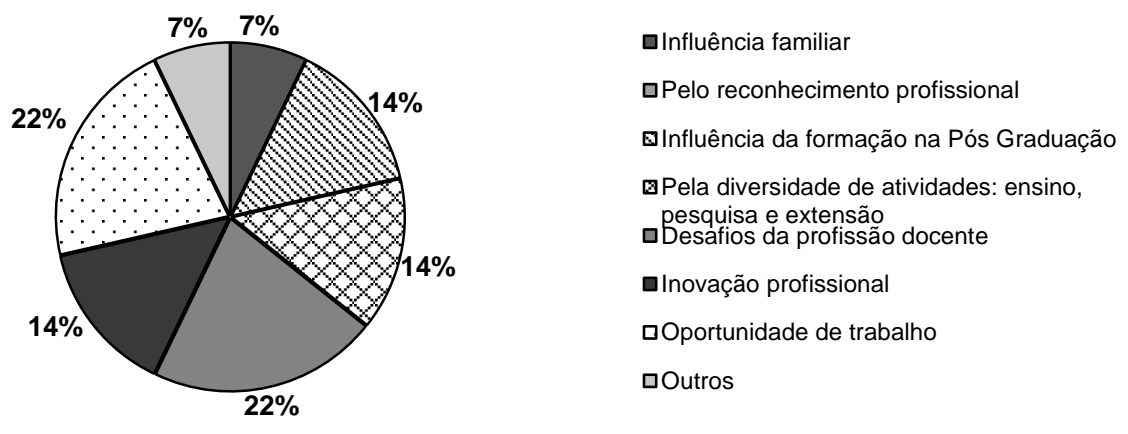

Fonte: as autoras.

Segundo Huberman (1992), existem diferentes momentos na carreira docente, a partir dos quais é possível categorizar a etapa em que o profissional se encontra na profissão. Segundo os dados analisados, os professores participantes demonstram estar divididos quanto à fase do desenvolvimento profissional com que se identificam. Dois professores sinalizaram estarem na fase do questionamento da carreira ou do cotidiano da profissão, outros dois apontaram estar na fase da estabilidade profissional docente, assumindo, portanto, sua identidade profissional. Já outros dois professores participantes da pesquisa indicaram pertencer à fase da diversificação profissional, que, em outras palavras, refere-se à fase de experimentação.

Dentre as maiores dificuldades, que encontram no trabalho como professores universitários, apontados pelos participantes da pesquisa, estão as seguintes:

- Desinteresse em estudar e não comprometimento de acadêmicos;

- Tempo reduzido para escrever artigos e projetos, devido à complementação da renda tendo que trabalhar em outros espaços;

- Falta de apoio e acompanhamento do trabalho docente pelo coordenador de curso;

- As horas complementares para trabalhos de extensão e o engessamento burocrático. 
Esses são alguns apontamentos realizados pelos professores iniciantes, os quais podem ser percebidos como fatores de desestímulo à carreira docente.

Apesar disso, como pode ser observado no gráfico 5, do total de participantes, $71 \%$ afirmaram que as condições do trabalho docente universitário são adequadas, restando apenas $29 \%$ que negaram essa afirmação.

Gráfico 5- Respostas dos professores acerca das condições do trabalho docente universitário.

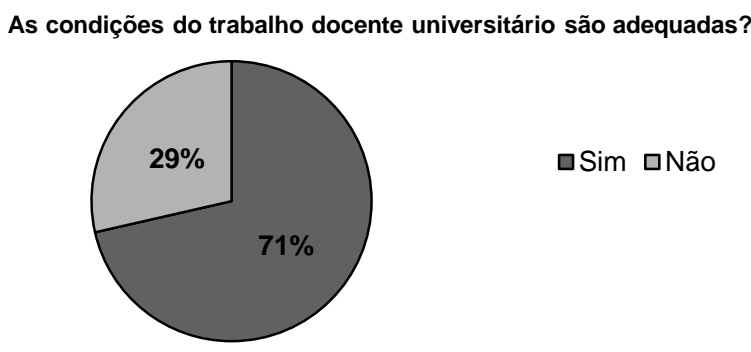

Fonte: as autoras.

Para saber quais elementos foram fundamentais para a constituição como docente universitário, levaram-se em consideração as seguintes escalas de atribuição: muito importante, importante e menos importante. De acordo com os dados obtidos, foi possível elencar alguns aspectos destacados pelos professores. De maneira geral, destacou-se como elementos muito importantes para a constituição como docente universitário: a formação continuada (71\%), diálogo formais e informais com colegas professores universitários (57\%), cursos de graduação (43\%), estudos pessoais (43\%) e participação em grupos de pesquisa (43\%). Todos os professores sinalizaram o aspecto experiência como docente no ensino superior, sendo importante na constituição do docente universitário, seguido de especialização, mestrado e/ou doutorado (86\%). Como menos importantes destacam-se: a atuação como docente na sala de aula na educação básica (71\%) e o retorno das avaliações discentes sobre o professor (57\%) (Gráfico 6).

GRÁFICo 6- Elementos que contribuem na constituição como docente universitário

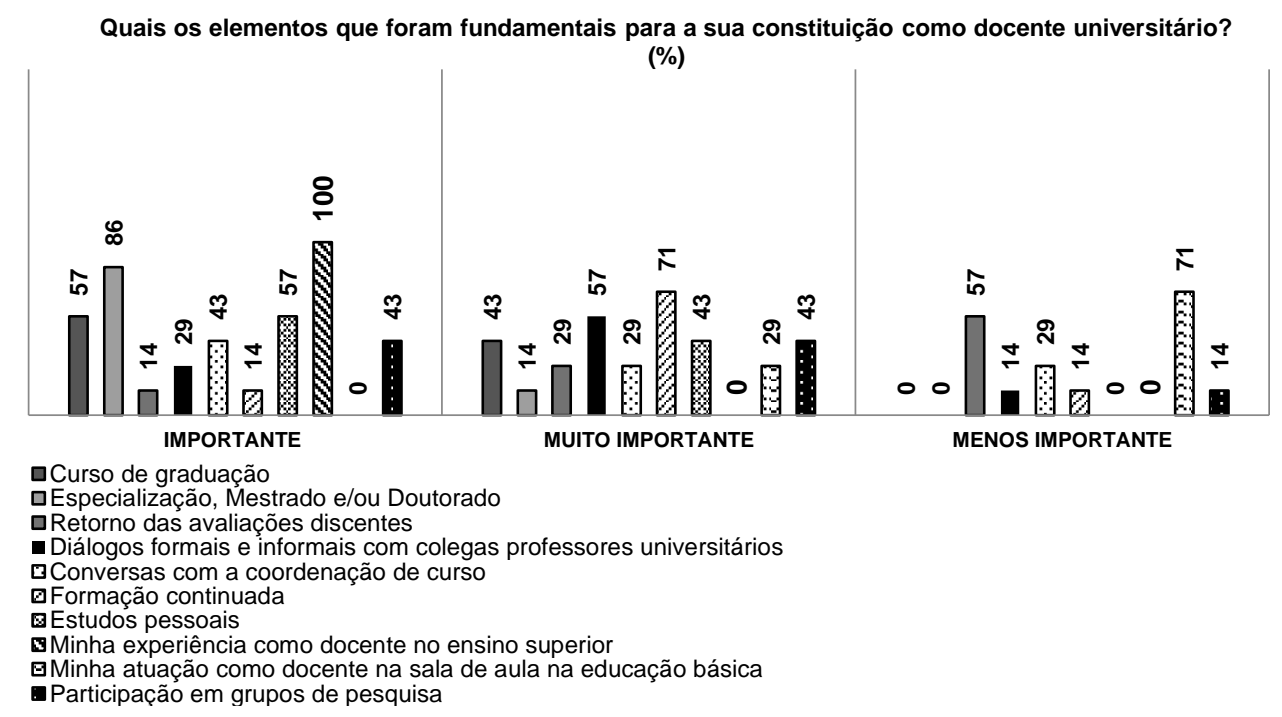

Fonte: as autoras. 
Diversos estudos e pesquisas vêm demonstrando que o professor universitário constrói sua identidade docente a partir de vivências familiares, dos seus professores, da própria experiência autodidata, das trocas com colegas e do feedback dos estudantes (PIMENTA, 2005; CASTAMAN, VIEIRA, OLIVEIRA, 2016; NÓVOA, 2017; LIMA, PIMENTA, 2018). Esses estudos convergem no que diz respeito ao reconhecimento da necessidade de programas institucionais de formação continuada para esses professores, principalmente os professores iniciantes, à medida que se observa uma lacuna existente a partir das suas formações acadêmicas.

No que diz respeito às temáticas consideradas relevantes pelos professores participantes para formação continuada e que poderiam contribuir para a sua prática docente por indicação foram, $57 \%$ do total, sobre metodologias ativas, seguida pelas temáticas currículo (15\%), procedimentos avaliativos e relações interpessoais com 14\% (Gráfico 7).

GRÁFICO 7- Temáticas consideradas relevantes pelos professores participantes para formação continuada

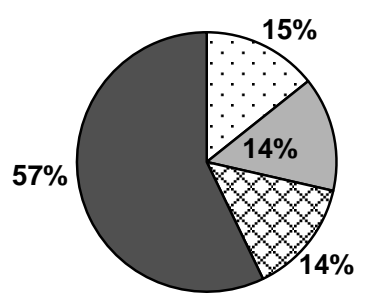

口Currículo

$\square$ Procedimentos Avaliativos

$\square$ Relações Interpessoais

$\square$ Metodologias Ativas

Fonte: as autoras.

Em relação aos aspectos do processo de ensino aprendizagem e avaliação da aprendizagem, foram levadas em consideração as seguintes escalas de atribuição: faz com frequência, faz esporadicamente e nunca faz. Analisando os dados obtidos em relação ao processo de ensino aprendizagem (Gráfico 8), ficou evidenciado que aula expositiva dialogada, com interação dos estudantes, é a mais comum entre as metodologias. Quanto às atividades que relacionam teoria e prática, e atividades envolvendo vídeos, filmes e documentários também se destacam entre as práticas docentes. Já as atividades elencadas pelos professores como esporádicas, destacamse os seminários, atividades orientadas em grupos e atividade com orientações individuais. Salienta-se aqui, a atividade que os professores nunca realizam, com o total de $100 \%$ dos participantes: júri simulado, seguida da atividade de produção de texto (43\%). Nenhum participante destacou outra atividade utilizada em relação ao processo de ensino aprendizagem na opção aberta dessa pergunta. 
GRÁFICO 8- Atividades relativas ao processo de ensino aprendizagem

Em relação ao processo ensino aprendizagem, quais atividades você realiza?

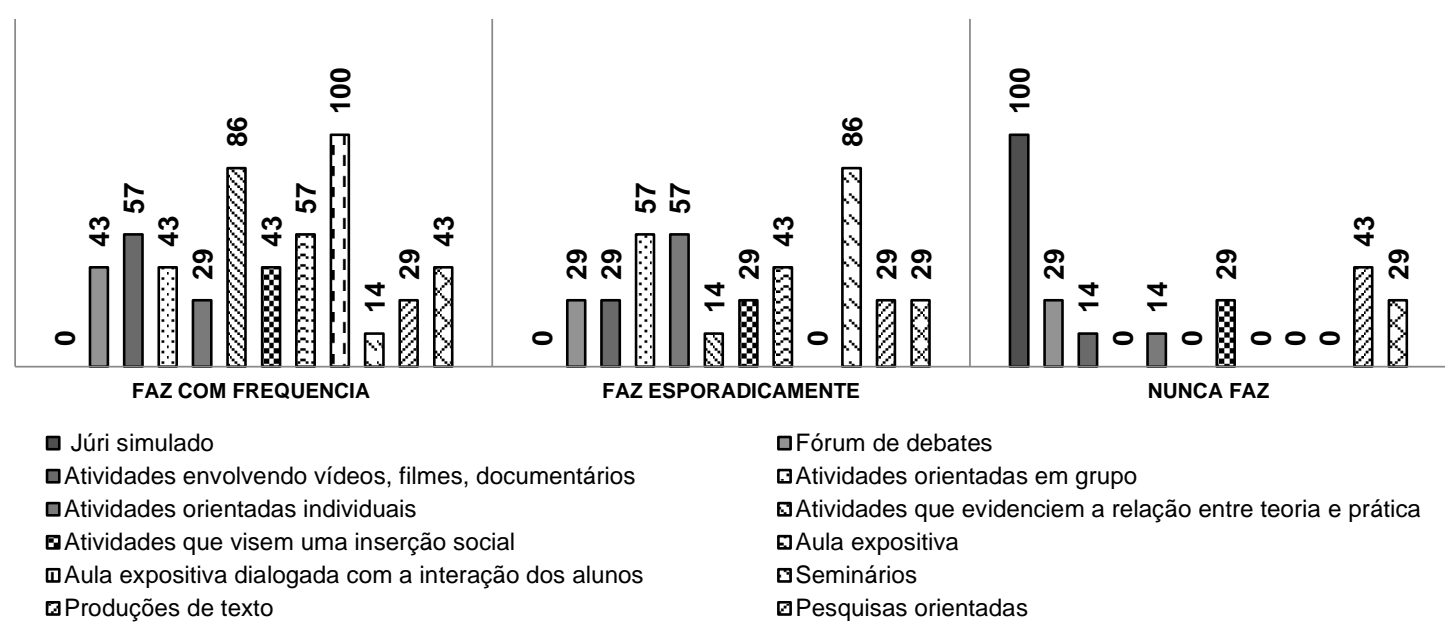

Fonte: as autoras.

Sabe-se que conhecimento pedagógico vai além de dominar algumas metodologias de ensino, necessita perceber os estudantes em suas especificidades, entendendo seu papel ético, político e social, buscando uma reflexão constante sobre a prática de ensino.

A respeito dos instrumentos de avaliação da aprendizagem, as provas objetivas foram elencadas pelos professores como as mais frequentemente utilizadas seguidas dos trabalhos individuais. Nas atividades avaliativas realizadas esporadicamente pelos professores, destacam-se os seminários, sucedidos pelas atividades de autoavaliações, provas discursivas e trabalhos em grupo. Entre as atividades que os professores nunca utilizam para a avaliação da aprendizagem, destaca-se o portfólio e provas orais, conforme Gráfico 9.

GRÁFICo 9- Instrumentos de avaliação da aprendizagem

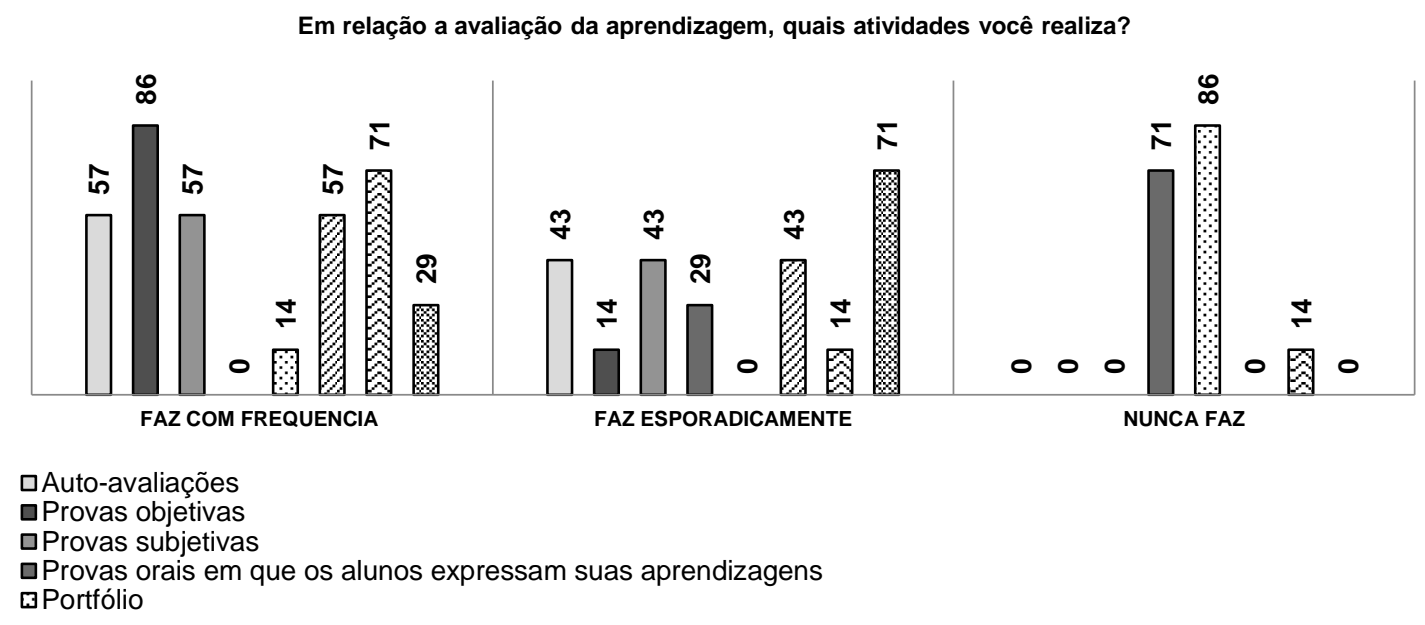

Fonte: as autoras.

No que diz respeito à pergunta aberta sobre a existência de outras atividades por eles utilizadas para avaliar o aprendizado, apenas dois professores destacaram o uso de lista 
de exercícios e produção de material, como catálogos e documentários utilizados como ferramentas para a avaliação da aprendizagem.

Por fim, analisaram-se os dados obtidos a respeito da pergunta aberta, a qual pretendeu pôr em discussão as avaliações institucionais do docente. A partir das respostas obtidas, pode-se evidenciar que a maioria não considera, pois acreditam que não expressam a realidade do contexto da sala de aula. Dois professores, entretanto, sinalizaram concordar com essas avaliações e afirmam que contribuem para repensar a prática docente.

\section{CONSIDERAÇÕES FINAIS}

O objetivo desta pesquisa tratou de analisar o perfil profissional dos professores iniciantes que atuam nos cursos de engenharia e os fios condutores de suas práticas pedagógicas. Desse modo, o presente estudo proporcionou compreender os desafios presentes nas universidades, no que tange à complexidade e à singularidade em ser professor iniciante, mapeando o perfil desse profissional que atua nos cursos de engenharias, assim como os elementos que fortalecem e dificultam a docência.

A análise dos dados sinalizou algumas considerações: os professores iniciantes trazem alguns saberes docentes que os caracterizam, muitos deles baseados no modelo que tiveram de seus professores ou de colegas de profissão, outros ainda, foram se constituindo a partir da sua própria prática docente. Ainda as análises decorridas neste estudo a partir dos dados apresentados pelos professores iniciantes, reforçam os apontamentos sobre a fragilidade da profissionalidade docente e sua trajetória formativa.

Dentre tantas mencionadas, como tempo reduzido para a docência, para pesquisa e extensão, engessamento dos processos, burocracias, falta de interesse dos acadêmicos, destaca-se ainda a falta de apoio e acompanhamento desse profissional em exercício pela instituição de ensino superior.

Assim, cabe propor políticas e ações para acompanhar os professores ingressantes, no sentido de contribuir no seu processo de constituição desde seus primeiros "atos pedagógicos", cooperando para a diminuição da insegurança, sensação de abandono e frustração, e assim, contribuir para seu desenvolvimento profissional.

Desse modo, este estudo proporcionou compreender os desafios presentes nas universidades, no que tange à complexidade e à singularidade em ser professor nos cursos de engenharia. Sabendo sobre a real constituição dos docentes nos primeiros anos de profissão, constatou-se a problematização em uma visão mais geral, possibilitando enxergar os desafios dessa prática inicial que gera no professor conflitos e inseguranças, pois estes percebem a incompletude de sua formação inicial como referência para as decisões sobre o que fazer e entender o que passa no cotidiano pedagógico de uma sala de aula.

Refletir a respeito do perfil do professor iniciante e os fios condutores que sustentam sua prática pedagógica foi fundamental para reforçar o olhar atento da universidade, dos coordenadores de cursos e dos formadores de professores. Pode-se considerar como evidente que o maior desafio é o apoio, o acompanhamento constante desse profissional, sua formação em serviço recebida nessa fase, o que possibilitará compartilhar os fios condutores das práticas pedagógicas, levando à superação dos desafios e a um maior crescimento profissional. 


\section{REFERÊNCIAS}

ALMEIDA, M. I. D. Formação do professor do ensino superior: desafios e políticas institucionais. São Paulo: Editora Cortez, 2012.

ALVES, T.; PINTO, J. M. R. Remuneração e características do trabalho docente no Brasil: um aporte. Cadernos de Pesquisa, v. 41, n. 143, p. 606-639, mai./ago. 2011.

BARDIN, Laurence. Análise de conteúdo. 4. ed. Lisboa: Edições70, 2010.

BAZZO, W. A.; PEREIRA, L. T. V.; VON LINSINGEN, I. Educação tecnológica: enfoques para o ensino de engenharia. 2. ed. rev. e ampl. Florianópolis: Ed. da UFSC, 2008.

BOLZAN, D. P. V.; POWACZUK, A. C. H.Iniciação à docência universitária: a tessitura da professoralidade. Acta Scientiarum: Human and Social Sciences. Maringa, v. 35, n. 2, p. 201-209, jul./dez. 2013.

BORGES, D. S.; TAUCHEN, G. Formação pedagógica dos professores na educação superior: experiências e possibilidades. Revista Contrapontos, v. 17, n. 2, p. 268-289, abr.jun. 2017.

BRASIL. Ministério da Educação. Instituto Nacional de Estudos e Pesquisas Educacionais Anísio Teixeira. Censo da Educação Superior-2016, Brasília, 2016.

CASTAMAN, A. S.; VIEIRA, A. M. D. P.; OLIVEIRA, D. A constituição da profissão docente: um estudo com professores da educação profissional. Revista Diálogo Educacional, v. 16, n. 50, p. 1009-1028, out/dez. 2016.

CAVACO, M. H. Ofício do professor: o tempo e as mudanças. In. Orgs. M

Nóvoa, A. Profissão professor. Porto: Porto, 1995. p. 155-191.

CONSELHO FEDERAL DE EDUCAÇÃO (CFE). Resolução n. 48, de 27 de abril de 1976. Fixa os mínimos de conteúdo e de duração do Curso de Graduação em Engenharia. Diário Oficial da União, Brasília, 21 de junho de 1976.

CONSELHO NACIONAL DE EDUCAÇÃO (CNE). Resolução CNE/CES 11 de março de 2002. Institui as Diretrizes Curriculares Nacionais do Curso de Graduação em Engenharia. Diário Oficial da União, Brasília, 9 de abril de 2002.

COORDENAÇÃO DE APERFEIÇOAMENTO DE PESSOAL DE NÍVEL SUPERIOR - CAPES. Portaria no 52 , de 26 de setembro de 2002, Brasília, 2002.

CUNHA, M. I. Reflexões e práticas em pedagogia universitária. Papirus Editora, 2007.

GARCIA, M. C. Formação de professores: para uma mudança educativa. Porto: Porto Editora, 1999.

HIDALGA, W. A. Engenheiros professores: uma primeira aproximação de suas concepções sobre os saberes docentes. São Bernardo, SP, 2006. Dissertação (Mestrado) - Programa de Pós-Graduação em Educação, Universidade Metodista de São Paulo, 2006.

HUBERMAN, M. O ciclo de vida profissional dos professores. In. Org. Nóvoa, A. Vidas de professores, Porto: Porto Editoras, v. 2, 1992. p. 31-61.

HUBERMAN, M. The professional life cycle of teachers. Teachers college record, v. 91, n. 1, 1989. p. 3157 ,

INSTITUTO NACIONAL DE ESTUDOS E PESQUISAS EDUCACIONAIS ANÍSIO TEIXEIRA. Sinopse Estatística da Educação Superior 2017: Número Total de Docentes em Exercício, por Organização Acadêmica e Regime de Trabalho, segundo a Unidade da Federação e a Categoria Administrativa das IES - 2017. Brasília: Inep, 2018.

JUNGES, K dos S; BEHRENS, M. A. Prática docente no Ensino Superior: a formação pedagógica como mobilizadora de mudança. Perspectiva, Florianópolis, v. 33, n. 1, p. 285-317, jan./abr. 2015.

LACLAUSTRA, V. A et al. Experiencias pedagogicas en ingeniería en Colombia una propuesta de mejoramiento del ejercicio docente. Revista de Ensino de Engenharia, v. 27, n. 3, p. 8-16, Edição especial, 2008. 
LAUDARES, J. B. A descoberta da docência por engenheiros-professores e suas representações. In: CONGRESSO BRASILEIRO DE ENSINO DE ENGENHARIA. v. 38, 2010.

LIMA, M. S.L.; PIMENTA, S. G. Estágio e docência. Cortez Editora, 2018.

MENESTRINA, T. C.; BAZZO, W. A. Alternativas para a formação do engenheiro: as concepções de Ciência, Tecnologia e Sociedade (CTS). In: XXXII CONGRESSO BRASILEIRO DE ENSINO DE ENGENHARIA, 32. Brasília-DF, 14 a 17 set. 2004.

NITSCH, J. C.; BAZZO, W. A.; TOZZI, M. J. Engenheiro-professor ou professor-engenheiro: reflexões sobre a arte do ofício. In: CONGRESSO BRASILEIRO DE EDUCAÇÃO EM ENGENHARIA. v. 22, p. 1-9, 2004.

NONO, M. A. Professores Iniciantes: o papel da escola em sua formação. Porto Alegre: Mediação, 2011. NÓVOA, A. (Org.). Vidas de professores. Porto: Porto Editora, 1992.

NÓVOA, A. Formação de professores e profissão docente. In: NÓVOA (Org.). Os professores e a sua formação. Lisboa: Dom Quixote, 1995. p. 13-33.

NÓVOA, A. (Org.). Os professores e a sua formação. Lisboa: Publicações Dom Quixote: Instituto de Inovação Educacional, 1995.

NÓVOA, A. Firmar a posição como professor, afirmar a profissão docente. Cadernos de Pesquisa, v. 47, n. 166, p. 1106-1133, 2017.

PAPI, S. O. G.; MARTINS, P. L. O. As pesquisas sobre professores iniciantes: algumas aproximações. Educação em Revista, v. 26, n. 3, p. 39-56, dez. 2010.

PIMENTA, S. G.; ANASTASIOU, L. G. C. Docência no ensino superior. São Paulo, Editora Cortez, 2002.

PIMENTA, S. G. Pesquisa-ação crítico-colaborativa: construindo seu significado a partir de experiências com a formação docente. Educação e pesquisa, v. 31, n. 3, p. 521-539, set./dez. 2005.

REALI, A. M. M. R.; TANCREDI, R. M. S. P.; MIZUKAMI, M. G. N. Programa de mentoria online: espaço para o desenvolvimento profissional de professoras iniciantes e experientes. Educação e Pesquisa, v. 34, n. 1, p. 77-95, jan./abr. 2008.

SAVIANI, D. Formação de professores: aspectos históricos e teóricos do problema no contexto brasileiro. Revista Brasileira de Educação, v. 14, n. 40, jan./abr. 2009.

SILVA JUNIOR, S. D.da.; COSTA, F. J. Mensuração e Escalas de Verificação: uma Análise Comparativa das Escalas de Likert e Phrase Completion. PMKT - Revista Brasileira de Pesquisas de Marketing, Opinião e Mídia, São Paulo,v5, p. 1-16, out. 2014.

TARDIF, M. $O$ trabalho docente, a pedagogia e o ensino: interações humanas, tecnologias e dilemas. Cadernos de educação, FaE/UFPel, Pelotas, v. 16, p. 15-47, jan.jun. 2001.

TARDIF, M. Saberes Docentes e Formação Profissional. 17. ed. Petrópolis, RJ: Vozes, 2014

VEIGA, I.P.A. Docência universitária na educação superior. Brasília: Instituto Nacional de Estudos e Pesquisas Anísio Teixeira, 2006.

Data da submissão: 13/02/2019

Data da aprovação: 08/07/2019 